\title{
Variability of Fusarium Crown Rot Tolerances Among Cultivars of Spring and Winter Wheat
}

\author{
Richard W. Smiley, Professor, and Hui Yan, Consulting Agricultural Statistician, Oregon State University, Colum- \\ bia Basin Agricultural Research Center, P.O. Box 370, Pendleton 97801
}

\begin{abstract}
Smiley, R. W., and Yan, H. 2009. Variability of Fusarium crown rot tolerances among cultivars of spring and winter wheat. Plant Dis. 93:954-961.

Crown rot caused by Fusarium pseudograminearum reduces the yield of wheat (Triticum aestivum) in Oregon. Observations of crown rot symptoms in traditional breeding and yield testing nurseries have not been useful for describing tolerance ratings of wheat cultivars. Yield data from inoculated experiments were therefore evaluated to determine if differences in cultivar response could be identified. A comparison of yields in inoculated and noninoculated plots was made for one group of spring wheat entries and four groups of winter wheat entries. Significant differences among spring wheat entries were identified and were validated against standards for tolerance and intolerance to F. pseudograminearum in Australia. Locally adapted and Australian standards exhibited a comparable range of yield reduction due to inoculation. Spring wheat tolerance reactions can be accurately described using as few as 24 yield comparisons. However, this screening method will not be practical for winter wheat due to stronger effects of year and location on the phenotypic tolerance response, requiring about 95 yield comparisons to accurately define the crown rot phenotype of a winter wheat cultivar.
\end{abstract}

Fusarium crown rot causes chronic and occasionally severe damage to wheat (Triticum aestivum L.) in the Pacific Northwest (PNW) states of Idaho, Oregon, and Washington $(4,12,24,27)$. In Oregon, Fusarium pseudograminearum (O'Donnell $\&$ Aoki) (=F. graminearum Group I = Gibberella coronicola) is more widespread and damaging than $F$. culmorum (Wm.G. Sm.) Sacc. and other species of the pathogen complex (24). Although F. pseudograminearum is capable of infecting leaves and inflorescences, the low mean annual precipitation ( 250 to $500 \mathrm{~mm}$ ) and the winter-dominant rainfall distribution of the PNW wheat belt almost always restrict infections in nonirrigated fields to the root cortex, scutellum, subcrown internode, crown, and/or lower culm $(12,19)$. Smiley et al. (22) reported that F. pseudograminearum reduced winter wheat yield as much as $35 \%$ in a commercial field and that the average reduction for 13 monitored fields was nearly $10 \%$. Yields were reduced as much as $61 \%$ when soils were inoculated with this pathogen. Crown rot has caused an even greater level of yield constraint in Australia $(3,6,8)$. Smiley et al. (22) concluded that damage from crown rot in the PNW is more widespread and

Corresponding author: Richard Smiley

E-mail: richard.smiley@ oregonstate.edu

Accepted for publication 3 June 2009.

doi:10.1094/PDIS-93-9-0954

(C) 2009 The American Phytopathological Society damaging than previously recognized and that aboveground symptoms are not always apparent under conditions of moderate infection and yield constraint. The increasing popularity of conservation tillage practices involving reduced or no primary tillage and greater cropping frequency also results in an increasing incidence and severity of crown rot $(20,28,32)$. Cultural management strategies are only partially effective and are not reliable for controlling damage caused by crown rot in the PNW $(4,11,12,19,20)$.

Commercially acceptable levels of genetic resistance are not yet available (3), but seedling and adult-plant tolerance (partial resistance) to $F$. pseudograminearum are known to reduce the amount of damage to stem base tissue and to increase wheat yields in Australia (29,31). Tolerance is defined as the ability of a plant to sustain the effects of a disease without dying or suffering serious injury or crop loss. In the PNW, winter wheat cultivars have been screened for tolerance in naturally infested soils during the past four decades, and the results for individual cultivars have been highly variable over years and test sites. As a result of this long-term testing, no cultivars in the PNW have been clearly identified as consistently tolerant to crown rot. Variability of reactions among sites was possibly associated with different species or mixtures of pathogen species present (24), different virulence characteristics among strains of the pathogens at different sites (21), or spatial heterogeneity of pathogen distribution within screening nurseries (8).
The degree of browning of the basal stem and the percentage of whiteheads often are correlated negatively with estimates of yield reduction by crown rot in individual experiments $(3,5,6,13,30)$, but measurement of culm discoloration is very labor intensive and is not always well correlated with estimates of grain yield reduction across years and environments in the PNW (22). Percentages of whiteheads in the crop canopy are a more easily measured indicator of disease severity within experiments (20), but whitehead development is also strongly affected by environmental conditions $(3,5,7,8,22)$ and may strongly underestimate crown rot incidence and the effect on yield $(8,22)$. Moreover, in the PNW, eyespot (Oculimacula yallundae (Wallwork \& Spooner) Crous \& W. Gams, and $O$. acuformis (Boerema, R. Pieters \& Hamers) Crous \& W. Gams), Cephalosporium stripe (Cephalosporium gramineum Y. Nisik. \& Ikata), take-all (Gaeumannomyces graminis (Sacc.) Arx \& Olivier var. tritici Walker), and Hessian fly (Mayetiola destructor (Say) also occur commonly and are expressed in part by whitehead development and browning of the basal culm $(1,12,17,23)$. Smiley et al. (22) concluded that "relationships between yield and quality of grain and proportions of either whiteheads or highly symptomatic basal culms were found to be too variable to predict quantitative crop damage caused by crown rot across environments in the PNW."

An inoculation method to directly measure the likely impact of crown rot on grain yield has emerged as the most efficient procedure for assessing tolerance in wheat cultivars. Since noninfested fields are uncommon in the PNW (24), a comparison of grain yield is made for adjacent plots that either receive supplemental inoculum of the pathogen or are noninoculated (30). This screening procedure is accomplished by inoculating the pathogen into the soil at the time of planting to create greater uniformity of the causal agent and of the disease intensity across the screening nursery $(22,30)$. Screening nurseries are typically performed as strip plots with individual wheat cultivars occurring side-by-side in replicated inoculated and noninoculated drill strips. Inoculation typically results in grain yields that are lower in inoculated than in noninoculated plots. Within an experiment in which at least some wheat entries have a much lower 
yield in inoculated than in noninoculated plots, the genotypes with comparable mean yields are assumed to be tolerant of the pathogen. Likewise, genotypes with yields that are considerably lower in inoculated than in naturally infested soil are considered intolerant. A range of genotypic responses is common within individual experiments in the PNW $(16,25,26)$, but differences among entries in these experiments are not always statistically significant.

Bockus et al. (2) described a method to calculate the number of experimental repetitions needed to achieve a given level of accuracy (margin of error) for assigning a phenotypic reaction of wheat cultivars to four foliar diseases. Applying a goal of defining the phenotypic response at the 95\% confidence interval, they determined that 20 to 47 observations ( 5 to 12 successful experiments with four replicates per treatment) were required, depending upon the specific disease, to define the phenotypic response of a wheat cultivar that exhibited an average amount of variability among repeated observations. The method uses the standard deviations among wheat entries in each experiment to calculate the probability for achieving an "accurate" assignment of the genotypic response. The variable response of cultivars to crown rot over years and across sites $(8,18,22,25)$ appears amenable to evaluation using the margin-of-error method described by Bockus et al. (2). It was therefore of interest to apply that approach to an evaluation of variability for the phenotypic reaction to crown rot in PNW wheat.

The objectives of this research were to evaluate the variability of $F$. pseudograminearum tolerance reactions among selected spring and winter wheat cultivars and breeding lines in eastern Oregon, and to estimate the number of experimental observations required to accurately define the phenotypic response for a typical cultivar or line. Data for these analyses were taken from the largest possible common group of entries planted over the largest possible number of sites and years, while also using the same seed drill and experimental procedures, including the identity and proportions of $F$. pseudograminearum isolates in the inoculum mixture.

\section{MATERIALS AND METHODS}

Experiments were performed from 2000 to 2008 at Oregon State University's Columbia Basin Agricultural Research Center's stations at Pendleton and Moro, OR. Mean annual precipitation at Pendleton and Moro is 442 and $282 \mathrm{~mm}$, respectively. The soil at both locations was a deep $(>1.5 \mathrm{~m})$ Walla Walla silt loam: coarse-silty, mixed, superactive, mesic Typic Haploxerolls. Different fields were used each year at each location due to the winter wheat-summer fallow rotation practiced in the region (15).

Seed of spring and winter wheat cultivars and lines was supplied by wheat breeders and pathologists at Oregon State University, Washington State University, and the International Center for Wheat and Maize Improvement (CIMMYT). Seed of Australian cultivars that have been well characterized for tolerance or intolerance to $F$. pseudograminearum $(5,29-31)$ were supplied by the South Australian Research and Development Institute and Queensland Department of Primary Industries. An Australian standard for intolerance to crown rot is Puseas. Standards for tolerance include 2-49, Gala, and Sunco. Sunco carries adult-plant resistance and is generally less tolerant than 2-49, which exhibits seedling resistance. In seed increase plots where crown rot is not limiting to yield, Sunco, when planted as a winter wheat, produces yields about the same as PNW-adapted winter wheat cultivars such as Stephens during years when winter damage does not occur in facultative cultivars such as Sunco (R. W. Smiley, unreported data). Likewise, yields of Sunco planted during the spring in the PNW are approximately $60 \%$ of yields when this cultivar is planted as a winter wheat, which closely approximates comparative yields of facultative wheat cultivars adapted to the PNW. Seed was treated with benomyl (Benlate; DuPont Crop Protection, Wilmington, DE) fungicide at $0.225 \mathrm{~g}$ a.i. $/ \mathrm{kg}$ seed to reduce or eliminate seedling damping-off associated with $F$. pseudograminearum (30).

Seed was planted into conventionally tilled (chisel plow and rod weeder; 15) summer fallow following winter wheat harvested either 6 months earlier for spring wheat or 14 months earlier for winter wheat. All plantings were made using a John Deere HZ split-packer deep-furrow drill with four hoe-type openers at $36-\mathrm{cm}$ row spacing into plot areas from $1.5 \times 6 \mathrm{~m}$ to $3 \times 9 \mathrm{~m}$, depending upon experiment. Winter wheat seed was planted from early to mid-September at rates from 194 to 250 seeds per $\mathrm{m}^{2}$. Seeding depths were from 5 to $10 \mathrm{~cm}$, with seed placed about $2 \mathrm{~cm}$ into moist soil at the bottom of a drill row, resulting in an overburden of air-dry soil up to $4 \mathrm{~cm}$ deep. Spring wheat was planted from early to late March at rates from 250 to 270 seeds per $\mathrm{m}^{2}$ and shallow depths from 3 to $4 \mathrm{~cm}$, resulting in seed placement into moist soil with an overburden of moist soil up to $4 \mathrm{~cm}$ deep. Fertilizer rates were determined from results of soil testing, and fertilizers were applied uniformly across each experimental area using a shank applicator before planting. Herbicides were applied in accordance with industry standards for weed species present at each experimental site.

$F$. pseudograminearum strains used to inoculate soil were isolated from infected crowns of winter wheat during 1993 and 1994 (24). Pathogen identification was initially based upon morphological features on half-strength potato dextrose and wheat-leaf agar media (10) and confirmed using polymerase chain reaction (PCR) procedures $(14,33)$. Isolates were stored on silica beads at $4{ }^{\circ} \mathrm{C}$ and autoclaved barley seed at $-80^{\circ} \mathrm{C}$. Five isolates $(93-82-03,94-$ 006-13, 94-32-06, 94-44-09, and 94-81-11) were selected to represent a range of geographic origins and virulence ratings to wheat seedlings in greenhouse tests. Isolates were from farms in Sherman and Wasco counties in Oregon (three isolates) and in Walla Walla County in Washington (two isolates). These isolates had virulence ratings ranging from 4.8 to 6.0 on a 0 to 7 scale in preliminary greenhouse assays: 0 $=$ avirulent and $7=$ highly virulent causing severe crown rot symptom development and stunting of seedling growth (unpublished data). Each isolate was grown on 0.2 -strength potato dextrose agar medium and seeded individually onto twiceautoclaved millet seeds. Colonized millet was air-dried and stored at room temperature (ca. $24^{\circ} \mathrm{C}$ ) in paper bags. Inoculum of each isolate was sieved to eliminate clumps and then blended in equal proportions to form a single composite before being applied to soil.

Wheat entries were planted with and without inoculum of $F$. pseudograminearum. Inoculum was banded above the wheat seed so the coleoptile would pass through the infested zone prior to seedling emergence $(5,30)$. Millet seed was metered from a Gandy fertilizer dispenser mounted on the grain drill, and dispensed through an adjustable-depth tube mounted behind each drill opener. For the inoculum treatment, colonized millet seed was dispensed into soil at $2.3 \mathrm{~g} / \mathrm{m}$ of row and banded 1 to $2 \mathrm{~cm}$ above the wheat seed in all four drill rows. Control treatments were planted without dispensing millet seed. The experimental design was a strip-plot with inoculum treatment as main plot and cultivars (entries) as subplots in blocks replicated three to seven times depending on experiment.

Seedling emergence and crown rot incidence and severity were monitored in all experiments to ensure that yield responses were caused by the $F$. pseudograminearum inoculum. Evaluations of symptoms on subcrown internodes, crowns, basal stems, and/or whiteheads (20) are not reported in this paper and were only partially reported for individual experiments (25).

Grain was harvested from each plot using a Hege 140 small-plot combine in late July after grain had dried to less than $12 \%$ moisture. Yield comparisons for individual experiments were analyzed using the CoStat Statistical Software version 6.311 (CoHort Software, Monterey, CA). Inoculation treatment was the main plot factor, and wheat entry was the subplot factor. When effects were significant at $P<0.05$, means for factors were separated using Fisher's least significant difference test (LSD). Yield data were converted to a percent yield difference for inoculated compared to noninoculated plots to reduce 
bias caused by yield differences over years and locations. Yields were occasionally ( $<5 \%$ of observations) slightly higher for inoculated than for noninoculated plots. Percent yield differences in these instances were adjusted to zero. All data were therefore analyzed on the basis of a theoretical range of yield differences from zero to $100 \%$. The yield reduction data for individual experiments were evaluated by ANOVA using a 1-way randomized complete block model with wheat entry as the factor and replicates as blocks. Data for wheat entries occurring in multiple tests were pooled across locations and years and analyzed as 3-way randomized blocks with main effects for location, year, and wheat entry.

The number of observations (experiments $\times$ replicates) required to describe a phenotypic reaction at varying levels of statistical accuracy was determined using the margin-of-error analysis described by Bockus et al. (2). Measured yield data for uniform groups of spring wheat or winter wheat entries were accumulated across multiple years and locations. For spring wheat, the margin-of-error analysis was based upon 20 yield comparisons for each of 17 wheat entries evaluated during 2007 and 2008 in three experiments with two inoculation levels (plus or minus inoculum) and six or seven replicates per entry (680 data points). Four groups of winter wheat entries were evaluated. The first group included 28 yield comparisons for each of 16 wheat entries evaluated over 2 years (2007 and 2008) at two locations with two inoculum levels and seven replicates (896 data points). The second winter wheat group included 48 yield observations for seven wheat entries examined during 2000-2003, 2007, and 2008 in nine experiments with three (2000-2001), four
(2002), or seven (2007-2008) replicates performed over a 6-year period at two locations (672 data points). The third group consisted of the removal of two experiments from the previously described nineexperiment group due to extraordinarily high yield reductions during tests at Moro and Pendleton during 2002 (37 observations, 560 data points). The fourth winter wheat group examined variability of the seven entries across 6 years at Pendleton only (27 observations, 420 data points).

Regression analysis was used to determine if means of the standard deviations of the percent yield reductions for all cultivars were associated with the magnitude of disease reduction. The independent variable was yield reduction and the standard deviation was the response or dependent variable for each observation within each of the three groups of wheat entries evaluated: spring wheat, and the previously described winter wheat groups 1 and 3 . Wheat entry was modeled as the random effect using both linear and quadratic associations.

The number of observations required to define a phenotypic reaction within a given range of accuracy compared to the "true" value was calculated (2) using the formula:

$$
\left(t_{\alpha / 2, n-1}\right)(s /{ } n)=M O E
$$

where $t_{\alpha / 2, n-1}$ is the $(1-\alpha / 2)$ quantile of the $t$ distribution with $n-1$ degrees of freedom, $n$ is the number of observations required, $s$ is the standard deviation of the obtained ratings, and $M O E$ (margin of error) is the prespecified deviation of the obtained ratings from the true rating. The calculation assumes that each entry is characterized as having the average amount of variability among replicates and experiments. We initially desired to de- scribe the phenotypic reactions at a level of accuracy within $\pm 5 \%$ of the "true" value. The acceptable margin of error at $\pm 5 \%$ of the theoretically correct assignment for an entry with a true average yield reduction of $10 \%$ may therefore have been observed to have ratings ranging from 5 to $15 \%$ in our tests. If that level of accuracy was not attained during the analysis, it became important to determine the number of observations required to attain that level of accuracy, assuming that data for future experiments would have similar standard deviations and a similar range of variability in phenotypic response. The projected number of observations required was computed using equation 1 with the significance level $\alpha$ set at 0.05 to calculate the associated value of $n$. A plot summarizing the relationship between $M O E$ and $n$ for the average of all wheat entries within each of the five groups (spring wheat, and four groups of winter wheat) was prepared by plotting the mean of $n$ for all entries in each group at each specified MOE. Because high numbers of field observations were predicted for winter wheat, we followed Bockus et al. (2) by also calculating the number of observations required to meet a margin of error of $\pm 10 \%$.

\section{RESULTS}

Yields of spring wheat entries were not reduced by Fusarium crown rot in a drought-stressed planting in which stand establishment was irregular and grain yields were very low at Moro during 2008, and this experiment was excluded from subsequent analyses. Mean yield reductions for spring wheat entries in individual experiments at Moro in 2007 and at Pendleton in 2007 and 2008 were 15, 5, and $6 \%$, respectively (Table 1 ). Analysis of the

Table 1. Percent yield reduction for 17 spring wheat entries in three experiments inoculated with Fusarium pseudograminearum during 2007 and 2008 at Moro and Pendleton, OR

\begin{tabular}{|c|c|c|c|c|c|c|c|c|}
\hline \multirow[b]{3}{*}{ Entry } & \multicolumn{4}{|c|}{ Yield reduction from inoculation $(\%)^{\mathrm{z}}$} & \multicolumn{4}{|c|}{ Relative rank of reduction (\#1 - \#17) } \\
\hline & \multirow{2}{*}{$\begin{array}{c}\text { Moro } \\
2007\end{array}$} & \multicolumn{2}{|c|}{ Pendleton } & \multirow[b]{2}{*}{ Mean } & \multirow{2}{*}{$\begin{array}{c}\text { Moro } \\
2007\end{array}$} & \multicolumn{2}{|c|}{ Pendleton } & \multirow[b]{2}{*}{ Mean } \\
\hline & & 2007 & 2008 & & & 2007 & 2008 & \\
\hline $2-49$ & $6.4 \mathrm{c}$ & $0.9 \mathrm{a}$ & $4.2 \mathrm{bc}$ & 3.9 & 2 & 2 & 7 & 4 \\
\hline Jefferson & $8.7 \mathrm{bc}$ & $3.0 \mathrm{a}$ & $2.3 \mathrm{c}$ & 4.6 & 6 & 4 & 1 & 4 \\
\hline Gala & $3.7 \mathrm{c}$ & $2.9 \mathrm{a}$ & $8.2 \mathrm{abc}$ & 4.9 & 1 & 3 & 13 & 6 \\
\hline Tara 2002 & $8.2 \mathrm{bc}$ & $5.3 \mathrm{a}$ & $3.7 \mathrm{bc}$ & 5.7 & 4 & 8 & 4 & 5 \\
\hline Sunco & $8.6 \mathrm{bc}$ & $5.0 \mathrm{a}$ & $4.1 \mathrm{bc}$ & 5.9 & 5 & 6 & 5 & 5 \\
\hline Macon & $7.8 \mathrm{bc}$ & $7.8 \mathrm{a}$ & $5.7 \mathrm{c}$ & 7.1 & 3 & 15 & 11 & 10 \\
\hline Penawawa & $13.5 \mathrm{abc}$ & $5.7 \mathrm{a}$ & $2.6 \mathrm{c}$ & 7.3 & 9 & 10 & 2 & 7 \\
\hline СТ030799 & $13.1 \mathrm{abc}$ & $6.2 \mathrm{a}$ & $3.6 \mathrm{bc}$ & 7.6 & 8 & 12 & 3 & 8 \\
\hline СТ020615 & $13.0 \mathrm{abc}$ & $5.2 \mathrm{a}$ & $8.2 \mathrm{abc}$ & 8.8 & 7 & 7 & 14 & 9 \\
\hline Alpowa & $16.8 \mathrm{abc}$ & $4.7 \mathrm{a}$ & $4.9 \mathrm{bc}$ & 8.8 & 12 & 5 & 9 & 9 \\
\hline Wawawai & $21.8 \mathrm{ab}$ & $0.8 \mathrm{a}$ & $4.2 \mathrm{bc}$ & 9.0 & 14 & 1 & 6 & 7 \\
\hline Seri & $16.3 \mathrm{abc}$ & $5.8 \mathrm{a}$ & $5.8 \mathrm{abc}$ & 9.3 & 10 & 11 & 12 & 11 \\
\hline Calorwa & $16.5 \mathrm{abc}$ & $10.3 \mathrm{a}$ & $5.6 a b c$ & 10.8 & 11 & 17 & 10 & 13 \\
\hline $302-5$ & $23.2 \mathrm{a}$ & $6.8 \mathrm{a}$ & $4.4 \mathrm{bc}$ & 11.5 & 15 & 14 & 8 & 12 \\
\hline Eden & $21.7 \mathrm{ab}$ & $6.7 \mathrm{a}$ & $11.7 \mathrm{a}$ & 13.4 & 13 & 13 & 17 & 14 \\
\hline Otis & $23.5 \mathrm{a}$ & $5.6 \mathrm{a}$ & $11.5 \mathrm{a}$ & 13.5 & 16 & 9 & 16 & 14 \\
\hline Puseas & $24.1 \mathrm{a}$ & $9.6 \mathrm{a}$ & $9.6 \mathrm{ab}$ & 14.4 & 17 & 16 & 15 & 16 \\
\hline Mean & 14.5 & 5.4 & 5.9 & & & & & \\
\hline
\end{tabular}

${ }^{\mathrm{z}}$ Comparison of yields of wheat entries in inoculated versus noninoculated plots. Means are from six replicates at Pendleton during 2008 and seven replicates at Moro and Pendleton during 2007. Means within a column followed by the same letter do not differ according to a protected least significant difference test $(P=0.05)$. 
yield response to inoculation in individual experiments revealed significant differences among entries at Moro during 2007 $(P<0.01)$ and at Pendleton during $2008(P$ $=0.05)$. Relative rankings of entries, with respect to percent yield reduction, varied among experiments. For instance, 2-49 and Jefferson were the lowest ranked entries overall, but 2-49 ranked as the second lowest entry in two experiments and ranked seventh in a third experiment. Likewise, the relative rankings for Jefferson ranged from first to sixth. Gala was among the lowest ranked entries in two tests but was ranked high in a third experiment. Sunco and Tara 2002 were also consistently low-ranking entries in these tests. Puseas was ranked overall as the least tolerant entry and had consistently high rankings for yield reduction. Otis and Eden also exhibited consistently high rankings.

Data for the three successful spring wheat experiments were analyzed as 2-way randomized blocks using location-year and wheat entry as factors. The interaction among these main effects was significant $(P<0.01)$ in each experiment. Data for 2007 were reanalyzed because successful experiments were completed at both locations during that year. The analysis confirmed that the location $\times$ entry interaction was significant $(P<0.01)$. Likewise, when data for experiments at Pendleton during 2007 and 2008 were analyzed separately, it was revealed that significant differences did not occur for wheat entry $(P=0.09)$, year $(P=0.28)$, or year $\times$ entry interaction $(P=0.67)$.

Mean yield reductions for winter wheat entries in four individual experiments during 2007 and 2008 were, respectively, 7 and $17 \%$ at Moro and 5 and $5 \%$ at Pendleton (Table 2). Yield reductions in individual experiments during 2007 differed significantly among wheat entries at Pendleton $(P=0.05)$ but not at Moro $(P=$ $0.06)$; yield reductions for individual entries ranged from a trace (CT980872) to $15 \%$ (CT000330) at Moro and from 2\% (Stephens) to $12 \%$ (Altay 2000) at Pendleton. As with spring wheat, relative rankings of the yield reduction for individual winter wheat entries varied among the four experiments (data not shown).

Data for the four winter wheat experiments were analyzed as 3-way randomized blocks using year, location, and wheat entry as factors. Main effects were significant for year $(P<0.01)$ and location $(P<$ $0.01)$ but not for wheat entry $(P=0.59)$. The location $\times$ year $\times$ entry interaction was not significant $(P=0.71)$. Two-way interactions were significant for location $\times$ year $(P<0.01)$ and year $\times$ entry $(P=0.02)$ but not for location $\times$ entry $(P=0.59)$, indicating different responses among entries when tested during different years. Yield reductions from crown rot were greater during 2008 than 2007 (11\% versus 6\%, $\mathrm{LSD}_{0.05}=2 \%$ ) and were greater at Moro than at Pendleton $\left(12 \%\right.$ versus $5 \%, \mathrm{LSD}_{0.05}$ $=2 \%)$. The overall most tolerant entries were ORSS-1757 and Stephens, and the least tolerant entries were Eltan and Tubbs 06, but the variation across experiments was high and these differences were not significant.

Data for seven cultivars were available for evaluation over nine location-years (2000-2003, 2007, and 2008). Mean yields, averaged across cultivars (Table 3 ), were reduced greatly by inoculation during 2002 ( $>50 \%$ at each location), very little during $2007(<4 \%)$, and at intermediate levels (11 to 19\%) during the other 4 years. At both Pendleton and Moro, the percent yield reduction due to crown rot varied from $<4 \%$ to $>50 \%$ during different years. Yield reductions differed significantly among cultivars in only three of nine experiments. During 2000 at Pendleton, the yield reductions among cultivars ranged from $3 \%$ for Madsen to $21 \%$ for Coda. Reductions among cultivars during 2002 ranged from $39 \%$ for Eltan to $85 \%$ for Coda at Pendleton, and from $29 \%$ for Sunco to $70 \%$ for Eltan at Moro. Winter damage did not appear to restrict yield of the facultative cultivar Sunco, as compared to PNW-adapted winter wheat entries, in any of nine location-years of these experiments. When data for the seven cultivars were averaged across location-years, the apparent mean yield reduction decreased in proportion to the number of experiments included in the calculation. For instance, for the three groupings that included experiments at both Pendleton and Moro, the overall yield reduction was 21,11 , and $9 \%$, respectively, for the groupings of nine, seven, and four locationyears (Table 3 ).

Data for the seven winter wheat cultivars pooled over nine location-years were analyzed as a 3-way randomized block (Table 4). Main effects were significant for year but not location or cultivar. The location $\times$ year $\times$ cultivar interaction was significant, as were the year $\times$ location and cultivar $\times$ location interactions. The range among means for individual cultivars (18 to $25 \%$ ) was very narrow (Table 3 ).

A similar analysis was performed after excluding the two experiments in which crown rot caused extensive yield reductions during 2002, assuming that the disease pressure during that year had the potential for overwhelming any inherent differences in tolerance that may have existed under more typical levels of disease severity. Main effects were significant for year and location but not cultivar (Table 4). The location $\times$ year $\times$ cultivar interaction was not significant, and the year $x$ location interaction was significant. The range among means for individual cultivars was slightly less for the seven location-year group (8 to 13\%) than for the nine location-year group (Table 3 ). Analysis of the four location-year group was essentially identical to that for the seven location-year group, with the range among cultivar means ( 7 to $12 \%$ ) again being less than for the nine location-year group (Tables 3 and 4). Further analysis of experiments located only at Pendleton, using 2way ANOVA (Table 4), revealed significant effects for cultivar and year, and also a cultivar $\times$ year interaction. The range among cultivar means was greater ( 8 to $19 \%$ ) than for the three other groupings discussed previously (Table 3 ).

The standard error of the mean for cultivars within individual experiments of the nine location-year winter wheat group varied from 0.6 to 4.0 for the least variable cultivar in each experiment to 2.6 to 14.4 for the most variable cultivar (data not

Table 2. Percent yield reduction for 16 winter wheat entries in four experiments inoculated with Fusarium pseudograminearum during 2007 and 2008 at Moro and Pendleton, OR

\begin{tabular}{|c|c|c|c|c|c|}
\hline \multirow[b]{3}{*}{ Entry } & \multicolumn{4}{|c|}{ Yield reduction from inoculation $(\%)^{\mathrm{z}}$} & \multirow[b]{3}{*}{ Mean } \\
\hline & \multicolumn{2}{|c|}{ Moro } & \multicolumn{2}{|c|}{ Pendleton } & \\
\hline & 2007 & 2008 & 2007 & 2008 & \\
\hline ORSS-1757 & $6.7 \mathrm{a}$ & $10.3 \mathrm{a}$ & $4.1 \mathrm{~b}$ & $3.2 \mathrm{a}$ & $6.1 \mathrm{a}$ \\
\hline Stephens & $4.8 \mathrm{a}$ & $16.5 \mathrm{a}$ & $1.8 \mathrm{~b}$ & $5.1 \mathrm{a}$ & $7.0 \mathrm{a}$ \\
\hline Bauermeister & $8.2 \mathrm{a}$ & $12.4 \mathrm{a}$ & $2.8 \mathrm{~b}$ & $6.1 \mathrm{a}$ & $7.4 \mathrm{a}$ \\
\hline Bruehl & $1.9 \mathrm{a}$ & $14.2 \mathrm{a}$ & $3.8 \mathrm{~b}$ & $9.6 \mathrm{a}$ & $7.4 \mathrm{a}$ \\
\hline СТ980872 & $0.3 \mathrm{a}$ & $20.9 \mathrm{a}$ & $1.9 \mathrm{~b}$ & $5.7 \mathrm{a}$ & $7.4 \mathrm{a}$ \\
\hline Sunco & $5.6 \mathrm{a}$ & $17.0 \mathrm{a}$ & $2.1 \mathrm{~b}$ & $5.3 \mathrm{a}$ & $7.5 \mathrm{a}$ \\
\hline Madsen & $4.0 \mathrm{a}$ & $12.6 \mathrm{a}$ & $6.8 \mathrm{ab}$ & $9.1 \mathrm{a}$ & $8.1 \mathrm{a}$ \\
\hline СТ000161 & $8.8 \mathrm{a}$ & $13.6 \mathrm{a}$ & $2.9 \mathrm{~b}$ & $7.8 \mathrm{a}$ & $8.3 \mathrm{a}$ \\
\hline BURBOT-6 & $4.7 \mathrm{a}$ & $13.9 \mathrm{a}$ & $6.4 \mathrm{ab}$ & $8.3 \mathrm{a}$ & $8.3 \mathrm{a}$ \\
\hline Coda & $1.8 \mathrm{a}$ & $19.8 \mathrm{a}$ & $2.4 \mathrm{~b}$ & $13.5 \mathrm{a}$ & $9.4 \mathrm{a}$ \\
\hline Weatherford & $3.1 \mathrm{a}$ & $22.2 \mathrm{a}$ & $3.6 \mathrm{~b}$ & $8.8 \mathrm{a}$ & $9.5 \mathrm{a}$ \\
\hline СТ000064 & $12.7 \mathrm{a}$ & $11.2 \mathrm{a}$ & $5.4 \mathrm{~b}$ & $8.3 \mathrm{a}$ & $9.6 \mathrm{a}$ \\
\hline Altay 2000 & $7.0 \mathrm{a}$ & $14.4 \mathrm{a}$ & $11.9 \mathrm{a}$ & $5.2 \mathrm{a}$ & $9.8 \mathrm{a}$ \\
\hline СТ000330 & $14.6 \mathrm{a}$ & $19.4 \mathrm{a}$ & $7.6 \mathrm{ab}$ & $2.5 \mathrm{a}$ & $11.0 \mathrm{a}$ \\
\hline Tubbs 06 & $8.7 \mathrm{a}$ & $22.3 \mathrm{a}$ & $7.5 \mathrm{ab}$ & $7.0 \mathrm{a}$ & $11.4 \mathrm{a}$ \\
\hline Eltan & $1.8 \mathrm{a}$ & $27.2 \mathrm{a}$ & $6.5 \mathrm{ab}$ & $12.0 \mathrm{a}$ & $11.9 \mathrm{a}$ \\
\hline Mean & 7.3 & 16.7 & 4.9 & 5.1 & \\
\hline
\end{tabular}

${ }^{\mathrm{z}}$ Comparison of yields of wheat entries in inoculated versus noninoculated plots. Means are from seven replicates in each of the four experiments. Means within a column followed by the same letter do not differ according to a protected least significant difference test $(P=0.05)$. 
shown). Standard errors ranged from 2.9 to 3.7 when data for the nine experiments were grouped, and were lower when data for the 2 years with high disease severity were excluded. There was no pattern among cultivars with respect to variability among replicates in individual experiments. The overall most tolerant cultivar, Sunco, had the lowest standard error of the mean at Pendleton during 2007 and 2008 and at both locations during 2008. However, Sunco was also the most variable cultivar at Moro during 2007. Coda was the overall most intolerant cultivar and was the most variable cultivar in three of nine experiments and the least variable cultivar in two other experiments. Likewise, Weatherford and Stephens were the most and the least variable cultivars in individual experiments.

Modeling of the linear relationship between standard deviation and percent yield reduction for individual wheat entries showed that the standard deviation became greater as the percent yield reduction became greater for all three groups of wheat (Fig. 1A to C). Quadratic models revealed that the standard deviation was greater for yield reductions in the midrange compared to the comparatively low or high levels of yield reduction for spring wheat (Fig 1A) and for the group of seven winter wheat cultivars examined over nine locationyears (Fig. 1C).

The relationship between the margin of error and the number of observations indicated that three of the data sets contained much less variability than two other data sets (Fig. 2). Data sets with the highest variability were the winter wheat groups (six and nine location-years) that included results from experiments during 2002 at Pendleton and/or Moro. The variability within the spring wheat data set was comparable with that in two groups of winter wheat: the four and seven location-year groups (Fig. 2). The calculated margin of error for defining the crown rot tolerance reaction for a spring wheat entry with an average level of variability was $5.3 \%$, based upon 20 observations in three experiments. The analysis estimated that 24 comparisons, as in four experiments with six replicates per treatment, were required to achieve a level of precision at a margin of error of $\pm 5 \%$ ( $95 \%$ confidence level) for spring wheat. Similarly, 27 comparisons would be required for the two restricted groups (four and seven location-years) of winter wheat. In contrast, when data for the 2002 experiments were included, the calculation projected that 95 and 27 observations would be required to assign a correct phenotypic reaction at the 95 and $90 \%$ confidence levels, respectively, for those two groups of winter wheat. It was also noted that the $90 \%$ confidence interval for these groups of winter wheat entries would be without meaning because the allowable range of the phenotypic response $( \pm 10 \%=20 \%$ allowable variability in mean yield response) for each cultivar would be greater than the 7 and $11 \%$ ranges of yield reductions actually measured among all genotypes in those two experiments.

\section{DISCUSSION}

This research evaluated the yield responses among spring and winter wheat entries when soils were inoculated with the crown rot pathogen $F$. pseudograminearum. The difference in grain yield in inoculated compared to noninoculated soil was applied as the measure of disease tolerance. The variability of response for each wheat entry was evaluated within individual experiments and when experiments were grouped across years and locations. The comparative yield responses

Table 3. Percent yield reduction of seven winter wheat cultivars in response to inoculation with Fusarium pseudograminearum in nine experiments conducted from 2000 to 2008 at Pendleton (six experiments) and Moro (three experiments), OR

\begin{tabular}{|c|c|c|c|c|c|c|c|c|c|c|c|c|c|}
\hline \multirow[b]{3}{*}{ Cultivar } & \multicolumn{9}{|c|}{ Nine individual experiments ${ }^{y}$} & & & & \\
\hline & \multicolumn{6}{|c|}{ Pendleton } & \multicolumn{3}{|c|}{ Moro } & \multicolumn{4}{|c|}{ Pooled experiments ${ }^{\mathrm{z}}$} \\
\hline & 2000 & 2001 & 2002 & 2003 & 2007 & 2008 & 2002 & 2007 & 2008 & $9 \exp$ & $7 \exp$ & $4 \exp$ & $6 \exp$ \\
\hline Bruehl & $12.1 \mathrm{ab}$ & $15.1 \mathrm{a}$ & $44.7 \mathrm{~d}$ & $9.6 \mathrm{a}$ & $3.8 \mathrm{a}$ & $9.6 \mathrm{a}$ & $64.2 \mathrm{ab}$ & $1.9 \mathrm{a}$ & $14.2 \mathrm{a}$ & 19.5 & 9.5 & 7.4 & 12.3 \\
\hline Coda & $20.9 \mathrm{a}$ & $18.4 \mathrm{a}$ & $85.1 \mathrm{a}$ & $16.3 \mathrm{a}$ & $2.4 \mathrm{a}$ & $13.5 \mathrm{a}$ & $49.5 \mathrm{bc}$ & $1.8 \mathrm{a}$ & $19.8 \mathrm{a}$ & 25.3 & 13.3 & 9.4 & 18.5 \\
\hline Eltan & $7.5 \mathrm{ab}$ & $10.8 \mathrm{a}$ & $39.4 \mathrm{~d}$ & $24.4 \mathrm{a}$ & $6.5 \mathrm{a}$ & $12.0 \mathrm{a}$ & $69.7 \mathrm{a}$ & $1.8 \mathrm{a}$ & $27.2 \mathrm{a}$ & 22.1 & 12.9 & 11.9 & 14.2 \\
\hline Madsen & $3.1 \mathrm{~b}$ & $13.6 \mathrm{a}$ & $65.3 \mathrm{abc}$ & $14.7 \mathrm{a}$ & $6.8 \mathrm{a}$ & $9.1 \mathrm{a}$ & $56.5 \mathrm{abc}$ & $4.0 \mathrm{a}$ & $12.6 \mathrm{a}$ & 20.6 & 9.1 & 8.1 & 10.5 \\
\hline Stephens & $20.8 \mathrm{a}$ & $10.1 \mathrm{a}$ & $67.8 \mathrm{abc}$ & $13.9 \mathrm{a}$ & $1.8 \mathrm{a}$ & $5.1 \mathrm{a}$ & $47.4 \mathrm{bc}$ & $4.8 \mathrm{a}$ & $16.5 \mathrm{a}$ & 20.9 & 10.4 & 7.0 & 14.9 \\
\hline Sunco & $4.2 \mathrm{~b}$ & $9.1 \mathrm{a}$ & $78.3 \mathrm{ab}$ & $11.4 \mathrm{a}$ & $2.1 \mathrm{a}$ & $5.3 \mathrm{a}$ & $28.8 \mathrm{~d}$ & $5.6 \mathrm{a}$ & $17.0 \mathrm{a}$ & 18.0 & 7.8 & 7.5 & 8.2 \\
\hline Weatherford & $7.8 \mathrm{ab}$ & $11.1 \mathrm{a}$ & $65.4 \mathrm{abc}$ & $22.9 \mathrm{a}$ & $3.6 \mathrm{a}$ & $8.8 \mathrm{a}$ & $44.3 \mathrm{c}$ & $3.1 \mathrm{a}$ & $22.2 \mathrm{a}$ & 21.0 & 11.4 & 9.4 & 14.0 \\
\hline Mean & 10.9 & 12.6 & 63.7 & 16.2 & 3.9 & 9.1 & 51.5 & 3.3 & 18.5 & 21.1 & 10.6 & 8.7 & 13.2 \\
\hline
\end{tabular}

y Comparison of yields of cultivars in inoculated versus noninoculated plots. Means for experiments during 2000, 2001, and 2003 are from three replicates. Means for experiments during 2002 are from four replicates, and means for experiments during 2007 and 2008 are from seven replicates. Means followed by the same letter within a column do not differ according to a protected least significant difference test $(P=0.05)$.

z $9 \exp =$ nine individual experiments, 7 exp = all except two experiments with extraordinarily high yield reductions at each location during 2002, 4 exp $=$ experiments conducted at each location during 2007 and 2008, and 6 exp = experiments conducted over 6 years at Pendleton.

Table 4. Effect of cultivar, year, location, and their interactions on percent yield reduction in response to inoculation with Fusarium pseudograminearum for seven winter wheat cultivars tested from 2000 to 2008 at Moro and Pendleton, OR

\begin{tabular}{|c|c|c|c|c|c|c|c|c|c|c|c|c|}
\hline \multirow[b]{2}{*}{ Source } & \multicolumn{3}{|c|}{9 location-years, $2000-2008^{z}$} & \multicolumn{3}{|c|}{7 location-years, 2000-2008 } & \multicolumn{3}{|c|}{4 location-years, 2007-2008 } & \multicolumn{3}{|c|}{6 years at Pendleton, 2000-2008 } \\
\hline & df & $F$ & $P>F$ & df & $F$ & $P>F$ & df & $F$ & $P>F$ & df & $F$ & $P>F$ \\
\hline \multicolumn{13}{|c|}{ Main effects } \\
\hline Cultivar & 6 & 1.72 & 0.1144 & 6 & 1.59 & 0.1507 & 6 & 0.94 & 0.4657 & 6 & 2.96 & 0.0091 \\
\hline Year & 5 & 192.89 & $<0.0001$ & 4 & 20.35 & $<0.0001$ & 1 & 60.10 & $<0.0001$ & 5 & 177.89 & $<0.0001$ \\
\hline Location & 1 & 0.70 & 0.6040 & 1 & 11.00 & 0.0011 & 1 & 10.93 & 0.0012 & & & \\
\hline \multicolumn{13}{|l|}{ Interaction } \\
\hline $\mathrm{C} \times \mathrm{Y}$ & 30 & 1.08 & 0.3652 & 24 & 1.32 & 0.1548 & 6 & 1.25 & 0.2846 & 30 & 3.52 & $<0.0001$ \\
\hline $\mathrm{C} \times \mathrm{L}$ & 6 & 2.83 & 0.0108 & 6 & 0.69 & 0.6611 & 6 & 0.68 & 0.6642 & & & \\
\hline $\mathrm{Y} \times \mathrm{L}$ & 2 & 19.28 & $<0.0001$ & 1 & 14.23 & 0.0002 & 1 & 14.15 & 0.0002 & & & \\
\hline $\mathrm{C} \times \mathrm{Y} \times \mathrm{L}$ & 12 & 6.61 & $<0.0001$ & 6 & 0.52 & 0.7921 & 6 & 1.52 & 0.7940 & & & \\
\hline Error & 266 & & & 224 & & & 161 & & & 161 & & \\
\hline Total & 334 & & & 278 & & & 194 & & & 208 & & \\
\hline
\end{tabular}

9 location-years $=$ nine individual experiments pooled across two locations and 6 years, 7 location-years $=$ the previous group after removal of the two experiments with extraordinarily high yield reductions during 2002, 4 location-years $=$ four experiments conducted at each of two locations during 2007 and 2008, and 6 location-years $=$ six experiments conducted over 6 years at Pendleton. 
were highly variable within experiments and across locations and years. Mean yield reductions due to crown rot during 2007 and 2008, across wheat entries, were similar for 17 spring wheat entries (4 to $14 \%$ ) and 16 winter wheat entries (6 to 12\%). Differences among winter wheat entries became less as more experiments were added into groups of pooled data.

Linear regression illustrated that the standard deviation among replicates for individual wheat entries increased as the percent yield reduction increased, as would be expected. However, it was also shown through quadratic regression analysis that the standard deviation tended to be higher for entries that were affected at an intermediate level of yield reduction compared to either a comparatively low or high level of response. This was interpreted to mean that the stability of yield response may be more acceptable for the more tolerant entries that are of particular interest for reducing yield constraints from crown rot, as compared to entries with intermediate reactions to crown rot.

The margin-of-error analysis described by Bockus et al. (2) indicated that it is possible to accurately characterize the tolerance characteristics of spring and winter wheat entries within an acceptable period of time, provided that experiments in the analysis do not include years in which disease severity is extraordinarily high. In the latter case, standard deviations became too great to allow accurate phenotypic distinctions among crown rot tolerance levels. Yield responses for spring wheat could be described with $95 \%$ confidence using as few as 24 comparisons of yields in inoculated versus noninoculated soil. Only a slightly greater number of comparisons were required to meet this standard for winter wheat groupings in which the year of highest disease severity was excluded. Reliable screening can therefore be accomplished and crown rot standards can be accurately identified for use in future field experiments in the PNW. This goal can be achieved by conducting four or five successful experiments with six replicates per treatment, or by six or seven experiments with four replicates. However, the mean range of tolerance levels was greater for spring wheat $(10 \%)$ than for winter wheat (5 to $7 \%$ ) entries. The range among winter wheat entries was too limited to be of practical value. It is therefore possible to evaluate advanced breeding lines of spring wheat in a timely manner before some of the lines become registered for use in commerce. In contrast, we were not able to achieve a similar level of confidence for winter wheat, due in part to the higher level of variability in yield response and to the greater influences of year and location on the tolerance response. Although spring wheat was not tested during 2002, the year in which disease pressure was extraordinarily high, calculations including that year for two groups of winter wheat led to estimates that about 95 observations would be required to define the tolerance response at the $95 \%$ confidence interval. Inclusion of data for years such as 2002 would have led to the conclusion that tolerance testing for winter wheat would be cost prohibitive and unlikely to be able to accurately screen advanced winter wheat breeding lines before some of the lines are released for commercial production.
Research in Australia has successfully evaluated crown rot tolerance for many years $(5,6,13,31)$. The production cycle in Australia averages 6 months from planting to harvest, which is more comparable to spring wheat (5 months) than to winter wheat (10 months) in the PNW. Several Australian standards were incorporated into these experiments even though they are not always well adapted to the environment to which they were subjected in the PNW, such as planting spring wheat
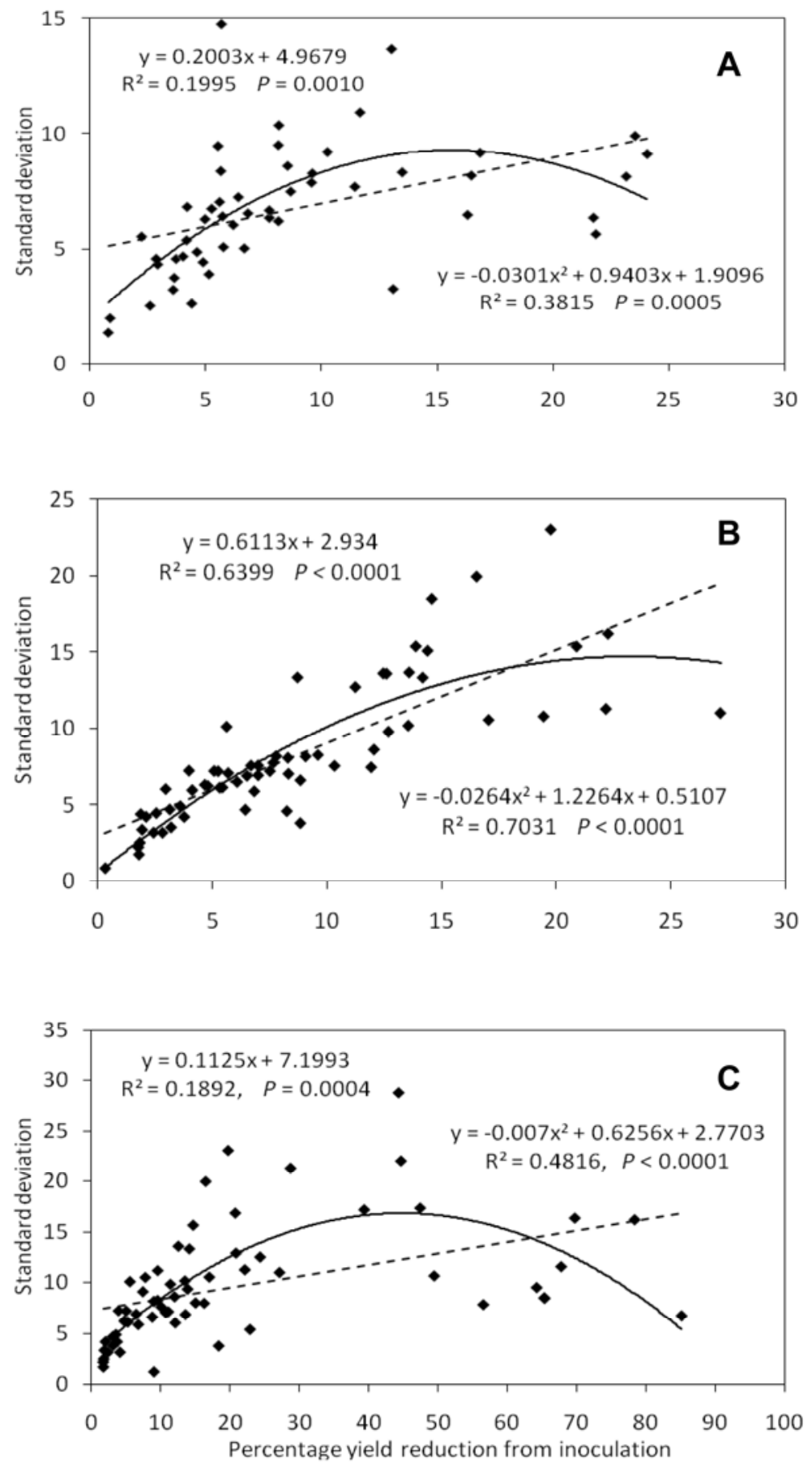

Fig. 1. Standard deviation of the Fusarium crown rot phenotypic reaction as a function of the percent yield reduction for individual wheat entries. A, 17 spring wheat entries evaluated across three locationyears; $\mathbf{B}, 16$ winter wheat entries evaluated across four location-years; $\mathbf{C}$, seven winter wheat entries evaluated across nine location-years. Linear and quadratic models were derived for the data. Note: axis scales are different among figures. 
near the end of the precipitation season in the PNW compared to the beginning of the rainy season in Australia, and planting into time in the PNW rather than cooling at the beginning of the milder winters in Australia. Nevertheless, the Australian standards performed against crown rot in the PNW as they have been characterized in Australia. The intolerant Puseas was significantly more affected by crown rot than the tolerant Australian standards 2-49, Gala, and Sunco. In our tests, Sunco was slightly less tolerant than 2-49 and Gala. The PNWadapted cultivars Jefferson and Tara 2002 were also comparatively tolerant, ranking between 2-49 and Sunco. The PNWadapted cultivars Otis and Eden were among the least tolerant cultivars, ranking similarly to Puseas. We propose that these four PNW-adapted cultivars can be used as tolerant and intolerant standards for future crown rot screening experiments with spring wheat in the PNW.

Higher variability of phenotypic responses and the limited levels of apparent differences in tolerance among entries in the winter wheat experiments made it difficult to identify reliable standards for tolerance and intolerance in future winter wheat screening nurseries. Although Sunco, an Australian wheat without a vernalization requirement typical of PNW winter wheat cultivars, was generally among the most tolerant of entries in these soils that are warming during the spring-

winter wheat trials, there were two strong exceptions to that observation: at Pendleton during 2002 and at Moro during 2008. It was therefore clear that the meaning and interpretation of data from future crown rot tolerance trials with winter wheat cultivars may be questionable unless the results are based upon a very large number of replicates and experiments spanning multiple testing sites and years.

The influence of drought on expression of crown rot symptoms and on yield suppression is well known $(3,4,12,19)$. Smiley (18) also reported that crown rot incidence was negatively correlated more significantly and more frequently with temperature than with moisture parameters in Oregon. Temperature and moisture in the seedzone and root-zone are strongly affected by the date on which winter wheat is planted in low-rainfall regions of the PNW. The great variability in crown rot expression over years and across regions of varying precipitation are therefore well known and anticipated. Comparisons of winter wheat cultivars across years in inoculation experiments reported here underscore the difficulties encountered in the past when unsuccessful attempts were made to define crown rot tolerances on the basis of symptom development in region-wide, noninoculated yield testing nurseries. It is now clear that complex influences of climatic and location factors cause considerable variability to occur among rankings of

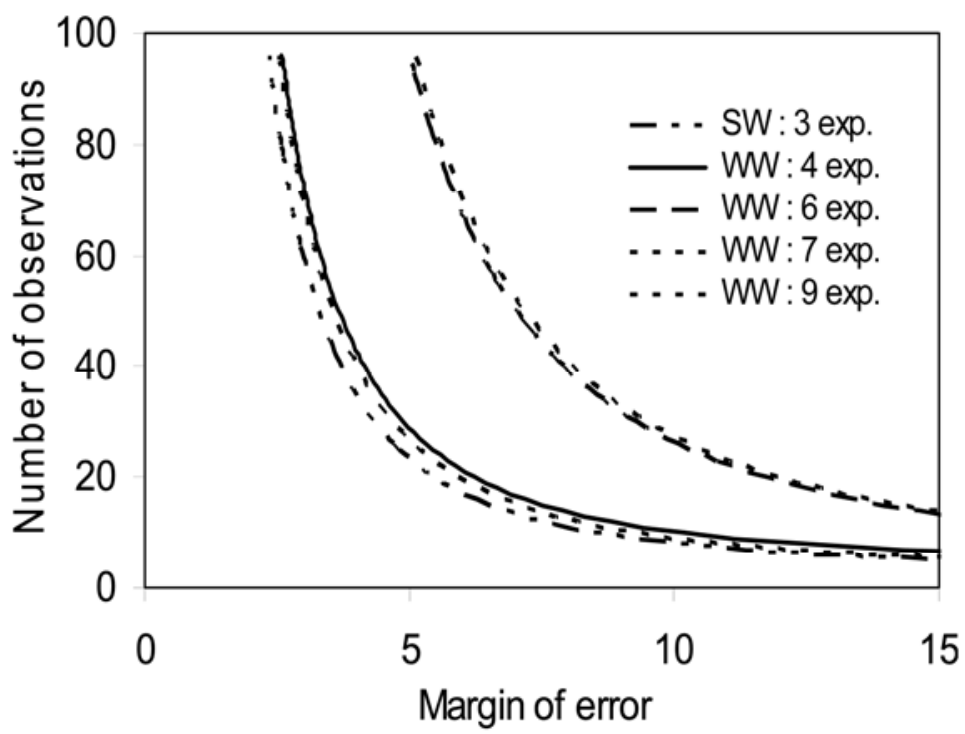

Fig. 2. Relationship between number of observations and the margin of error within data sets for five groups of wheat entries, based upon calculations using standard deviations observed in comparisons of grain yields in noninoculated soil and in soil inoculated with Fusarium pseudograminearum. The margin of error describes the precision (probability level) at which the crown rot tolerance reaction (phenotypic response) is described for a wheat entry that exhibits an average level of variability across a given number of observations (yield comparisons) from field experiments. Calculations were for: (i) three experiments (SW: 3 exp) with 17 spring wheat entries and six or seven replications (20 observations per entry) at Moro and Pendleton during 2007 and 2008; (ii) four experiments (WW: 4 exp) with 16 winter wheat entries and seven replications (28 observations) at Moro and Pendleton during 2007 and 2008; (iii) six experiments (WW: 6 exp) with seven winter wheat entries and three to seven replications (27 observations) at Pendleton from 2000 to 2008; (iv) seven experiments (WW: 7 exp) with seven winter wheat entries and three to seven replications (37 observations) at Moro and Pendleton from 2000 to 2008; and (v) nine experiments (WW: 9 exp) with seven winter wheat entries and three to seven replications (48 observations) at Moro and Pendleton from 2000 to 2008. crown rot responses for individual winter wheat cultivars. Tolerance to crown rot, particularly among winter wheat cultivars, appears to respond differently to the undefined effects of climate and location. For instance, the mean reduction in yield of commercial winter wheat cultivars (Table 3) was greater during 2008 than 2007 (19\% versus $3 \%)$ at the low-rainfall location (Moro), and there was a much lower difference in overall yield reductions $(9 \%$ versus $4 \%$ ) during the same years at the higher-rainfall location (Pendleton). In 2002, a year in which crown rot was especially damaging, mean yield reduction (52\% versus $64 \%$ ) for commercial winter wheat cultivars was severe at Pendleton as well as at Moro. Moreover, it also appeared that climatic factors exerted different influences on spring versus winter wheat. For instance, yields during 2007 and 2008 were reduced by about $5 \%$ for groups of both spring and winter wheat entries at Pendleton (Tables 1 and 2). At Moro, however, the mean reduction in winter wheat yield was only half that for spring wheat during 2007 (7\% versus $15 \%)$.

Greater variability of crown rot tolerance responses occurred among winter wheat compared to spring wheat entries tested across years and locations. The reason for this effect of wheat growth habit is not clear. It is possible that it was an expression of interactions among the lengths of the growing periods for spring and winter wheat, seasonal and annual temperature and moisture variables (18), variation of natural background level of crown rot in control plots caused by strains of native Fusarium spp. for which virulence is also affected differently by moisture and temperature variables $(21,24)$, or other such uncontrolled and uncontrollable factors.

In view of the challenges associated with distinguishing tolerance responses among winter wheat entries, and of the preponderance of winter wheat over spring wheat plantings in the PNW (15), it is important that attempts to manage losses from crown rot in winter wheat continue to focus on management of factors such as time of planting, rate of fertilizer application, and infested residue from previous crops $(3,4,11,12,19,20,28,32)$. Emphasis for future research with winter wheat should also be shifted from a definition of tolerance to introduction of resistance $(9,29,30)$, which will presumably be more stable across years and climates in the PNW.

\section{ACKNOWLEDGMENTS}

We thank Sandra Easley, Jennifer Gourlie, Erling Jacobsen, Karl Rhinhart, Jason Sheedy, Alison Thompson, and Paul Thorgersen (OSU research assistants and facility managers) for technical assistance and field and equipment maintenance. Wheat seed was supplied by James Peterson, Kimberlee Garland-Campbell, Kimberley Kidwell, Julie Nicol, Hugh Wallwork, and Graham Wildermuth. This research was funded by an OSU subcontract to the 
USDA-Agricultural Research Service (SCA\#585348-9-100; Control of Root Diseases of Wheat and Barley).

\section{LITERATURE CITED}

1. Bockus, W. W., Bowden, R. L., Hunger, R. M., Morrill, W. L., Murray, T. D., and Smiley, R. W., eds. 2009. Compendium of Wheat Diseases and Insects, 3rd ed. American Phytopathological Society, St. Paul, MN.

2. Bockus, W. W., Su, Z., Garrett, K. A., Gill, B. S., Stack, J. P., Fritz, A. K., Roozeboom, K. L., and Martin, T. J. 2007. Number of experiments needed to determine wheat disease phenotypes for four wheat diseases. Plant Dis. 91:103-108.

3. Burgess, L. W., Backhouse, D., Summerell, B. A., and Swan, L. J. 2001. Crown rot of wheat. Pages 271-294 in: Fusarium. B. A. Summerell, J. F. Leslie, D. Backhouse, W. L. Bryden, and L. W. Burgess, eds. American Phytopathological Society, St. Paul, MN.

4. Cook, R. J. 1981. Fusarium diseases of wheat and other small grains in North America. Pages 39-52 in: Fusarium: Diseases, Biology and Taxonomy. P. E. Nelson, T. A. Toussoun, and R. J. Cook, eds. Pennsylvania State University, University Park.

5. Dodman, R. L., and Wildermuth, G. B. 1987. Inoculation methods for assessing resistance in wheat to crown rot caused by Fusarium graminearum Group 1. Aust. J. Agric. Res. 38:473-486.

6. Dodman, R. L., Wildermuth, G. B., Klein, T. A., and Ellison, F. W. 1985. Field resistance of wheat cultivars to crown rot (Fusarium graminearum Group 1). Pages 167-168 in: Ecology and Management of Soilborne Plant Pathogens. C. A. Parker, A. D. Rovira, K. J. Moore, and P. T. W. Wong, eds. American Phytopathological Society, St. Paul, MN.

7. Klassen, J. A., Matthee, F. N., Marasas, W. F., and van Schalkwyk, D. J. 1992. Survey of Fusarium species associated with crowns of healthy-head and white-head wheat plants in the southern and western Cape Province. Phytophylactica 24:85-94.

8. Klein, T. A., Burgess, L. W., and Ellison, F. W. 1991. The incidence and spatial patterns of wheat plants infested by Fusarium graminearum Group 1 and the effect of crown rot on yield. Aust. J. Agric. Res. 42:399-407.

9. Mitter, V., Zhang, M. C., Liu, C. J., Ghosh, R., Ghosh, M., and Chakraborty, S. 2006. A highthroughput glasshouse bioassay to detect crown rot resistance in wheat germplasm. Plant Pathol. 55:433-441.

10. Nelson, P. E., Toussoun, T. A., and Marasas, W. F. O. 1983. Fusarium species: An Illustrated Manual for Identification. Pennsylvania
State University, University Park.

11. Ogg, A. G., Jr., Smiley, R. W., Pike, K. S., McCaffrey, J. P., Thill, D. C., and Quisenberry, S. S. 1999. Integrated pest management for conservation systems. Pages 97-128 in: Advances in Conservation Farming. E. L. Michalson, R. I. Papendick, and J. E. Carlson, eds. CRC Press, Boca Raton, LA.

12. Paulitz, T. C., Smiley, R. W., and Cook, R. J. 2002. Insights into the prevalence and management of soilborne cereal pathogens under direct seeding in the Pacific Northwest, U.S.A. Can. J. Plant Pathol. 24:416-428.

13. Purss, G. S. 1966. Studies of varietal resistance to crown rot of wheat caused by Fusarium graminearum Schw. Queensl. J. Agric. Anim. Sci. 23:475-498.

14. Schilling, A. G., Möller, E. M., and Geiger, H. H. 1996. Polymerase chain reaction-based assays for species-specific detection of Fusarium culmorum, $F$. graminearum, and $F$. avenaceum. Phytopathology 86:515-522.

15. Schillinger, W. R., Papendick, R. I., Guy, S. O., Rasmussen, P. E., and van Kessel, C. 2006. Dryland cropping systems in the western United States. Pages 365-393 in: Dryland Agriculture, 2nd ed. G. A. Peterson, P. W. Unger, and W. A. Payne, eds. Agron. Monogr. 23. American Society of Agronomy, Madison, WI.

16. Sheedy, J. G., Smiley, R. W., Thompson, A. L., and Easley, S. A. 2008. Field tolerance reaction of Pacific Northwest spring wheat cultivars to crown rot, 2007. Plant Dis. Manag. Rep. 2:CF003.

17. Smiley, R. W. 1996. Diseases of wheat and barley in conservation cropping systems of the semiarid Pacific Northwest. Am. J. Alternative Agric. 11:95-103.

18. Smiley, R. W. 2009. Water and temperature parameters associated with winter wheat diseases caused by soilborne pathogens. Plant Dis. 93:73-80.

19. Smiley, R. W., Backhouse, D., Lucas, P., and Paulitz, T. C. 2009. Diseases which challenge global wheat production - root, crown, and culm rots. Pages 125-153 in: Wheat: Science and Trade. B. F. Carver, ed. Wiley-Blackwell, Ames, IA.

20. Smiley, R. W., Collins, H. P., and Rasmussen, P. E. 1996. Diseases of wheat in long-term agronomic experiments at Pendleton, Oregon. Plant Dis. 80:813-820.

21. Smiley, R. W., Gourlie, J. A., Easley, S. A., and Patterson, L.-M. 2005. Pathogenicity of fungi associated with the wheat crown rot complex in Oregon and Washington. Plant Dis. 89:949957.

22. Smiley, R. W., Gourlie, J. A., Easley, S. A., Patterson, L.-M., and Whittaker, R. G. 2005.
Crop damage estimates for crown rot of wheat and barley in the Pacific Northwest. Plant Dis 89:595-604.

23. Smiley, R. W., Gourlie, J. A., Whittaker, R. G., Easley, S. A., and Kidwell, K. A. 2004. Economic impact of Hessian fly (Diptera: Cecidomyiidae) on spring wheat in Oregon and additive yield losses with Fusarium crown rot and lesion nematode. J. Econ. Entomol. 97:397-408.

24. Smiley, R. W., and Patterson, L.-M. 1996. Pathogenic fungi associated with Fusarium foot rot of winter wheat in the semiarid Pacific Northwest. Plant Dis. 80:944-949.

25. Smiley, R., Peterson, J., Gourlie, J., Whittaker, R., Patterson, L., Easley, S., Thompson, D. and Rhinhart, K. 2002. Influence of Fusarium crown rot on growth and yield of winter wheat and triticale. Biol. Cult. Tests Control Plant Dis. 17:S11.

26. Smiley, R., Peterson, J., Gourlie, J., Whittaker, R., Patterson, L., Easley, S., Thompson, D. Rhinhart, K., and Riera-Lizarazu, O. 2002. Influence of Fusarium crown rot on yield of winter and spring wheat. Biol. Cult. Tests Control Plant Dis. 17:S07.

27. Strausbaugh, C. A., Bradley, C., Koehn, A. C., and Forster, R. 2004. Survey of root diseases of wheat and barley in southeastern Idaho. Can. J. Plant Pathol. 26:167-176.

28. Summerell, B. A., Burgess, L. W., and Klein, T. A. 1989. The impact of stubble management on the incidence of crown rot of wheat. Aust. J. Exp. Agric. 29:91-98.

29. Wallwork, H., Butt, M., Cheong, J. P. E., and Williams, K. J. 2004. Resistance to crown rot in wheat identified through an improved method for screening adult plants. Australas. Plant Pathol. 33:1-7.

30. Wildermuth, G. B., and McNamara, R. B 1994. Testing wheat seedlings for resistance to crown rot caused by Fusarium graminearum Group 1. Plant Dis. 78:949-953.

31. Wildermuth, G. B., McNamara, R. B., and Quick, J. S. 2001. Crown depth and susceptibility to crown rot in wheat. Euphytica 122:397-405

32. Wildermuth, G. B., Thomas, G. A., Radford, B. J., McNamara, R. B., and Kelly, A. 1997. Crown rot and common root rot in wheat grown under different tillage and stubble treatments in southern Queensland, Australia. Soil Till. Res. 44:211-224

33. Williams, K. J., Dennis, J. I., Smyl, C., and Wallwork, H. 2002. The application of speciesspecific assays based on the polymerase chain reaction to analyse Fusarium crown rot of durum wheat. Australas. Plant Pathol. 31:119 127. 